\title{
Effect of the $W$ mutation, for white belly spot, on testicular germ cell differentiation in mice
}

\author{
K. Sawada, K. Sakamaki and Y. Nishimune* \\ Research Institute for Microbial Diseases, Osaka University Yamada-oka, Suita, Osaka 565, Japan
}

\begin{abstract}
Summary. The effect of the mutation for white belly spot controlled by the dominant gene $W$ on spermatogenesis in mice was examined by experimental cryptorchidism and its surgical reversal. The course of spermatogenesis from spermatogonia to spermatid was normal in intact testes of $W /+$ mice. In cryptorchid testes, there was no difference in the number and activity of Type A spermatogonia between the testes of $W /+$ and $+/+$ mice, in mitotic and labelling indices. Although surgical reversal of the cryptorchid testis resulted in regenerative differentiation of germ cells in both genotypes, the recovery of cell differentiation in the $W /+$ testis was slower than in the $+/+$ testis. There were fewer germ cells, such as intermediate-Type B spermatogonia or more advanced ones, in $W /+$ testes. On Day 17 after surgical reversal, cell associations in $W /+$ testes were abnormal and the numbers of intermediate-Type B spermatogonia, spermatocytes and spermatids were approximately $\sim 70,50$ and $15 \%$, respectively, of those in $+/+$ testes. These results indicate that the $W$ gene affects spermatogenic cell differentiation in adult mice.
\end{abstract}

Keywords: $W$ mutation; spermatogenesis; cryptorchidism; orchidopexy; mouse

\section{Introduction}

A double dose of dominant alleles at the $W$ locus for white belly spot has pleiotropic effects on sterility, macrocytic anaemia and a deficiency of melanocytes and mast cells (Russell, 1979). Deficiency of erythrocytes, melanocytes and mast cells is attributed to a defect in their precursor cells (McCulloch et al., 1964; Mayer \& Green, 1968; Russell \& Bernstein, 1968; Mayer, 1970; Kitamura et al., 1978). However, the mechanism of action of $W$ on germ-cell differentiation is not understood. The sterility of homozygotes with $W$ alleles results from the absence of germ cells in the fetal gonad. Proliferation and migration of the primordial germ cells to the genital ridge are disrupted in homozygotes with $W, W^{\vee}$ and $W^{j}$ alleles (Mintz, 1957; Mintz \& Russell, 1957). Postnatal differentiation of germ cells is also retarded in homozygotes with these alleles, but not in heterozygotes (Coulombre \& Russell, 1954). On the other hand, several alleles, e.g. $W^{35}, W^{38}, W^{40}$, $W^{42}$ and $W^{43}$, have deleterious effects on postnatal germ-cell differentiation, even in the heterozygous condition (Geissler et al., 1981), but the particular stage of spermatogenesis affected by $W$ mutations remains unclear. When investigating the effect of $W$ mutations on spermatogenesis, it is desirable to examine the testes of mice with normal numbers of blood cells and normal somatic elements of the gonad to eliminate secondary mutation effects.

In addition to normal differentiation of primordial germ cells, $W /+$ mice have normal blood cells and are fully fertile (Grüneberg, 1942; Russell \& Fondal, 1951). In the present study, the effects of the $W$ mutation on spermatogenesis were examined in heterozygous mice by experimental cryptorchidism and its surgical reversal. These techniques have proved effective in the study 
Table 1. Cell analysis of intact and cryptorchid testes of $W /+$ (white belly spot) and $t /+$ mice

\begin{tabular}{|c|c|c|c|c|}
\hline \multirow[b]{2}{*}{ Cell type } & \multicolumn{2}{|c|}{ Intact } & \multicolumn{2}{|c|}{ Cryptorchid } \\
\hline & $W /+$ & $+1+$ & $W /+$ & $+1+$ \\
\hline $\begin{array}{l}\text { Sertoli cells } \\
\text { Mitotic cells }\end{array}$ & $\begin{array}{c}345 \pm 38 \\
63 \pm 5\end{array}$ & $\begin{array}{r}302 \pm 21 \\
49 \pm 11\end{array}$ & $\begin{array}{c}485 \pm 79^{*} \\
43 \pm 16\end{array}$ & $\begin{array}{c}499 \pm 48^{*} \\
52 \pm 17\end{array}$ \\
\hline Spermatogonia & & & & \\
\hline $\begin{array}{l}\text { Type A } \\
\text { Intermediate-B }\end{array}$ & $\begin{array}{l}183 \pm 44 \\
151 \pm 48\end{array}$ & $\begin{array}{l}196 \pm 8 \\
140 \pm 45\end{array}$ & $242 \pm 33$ & $247 \pm 49$ \\
\hline $\begin{array}{l}\text { Spermatocytes } \\
\text { Resting primary }\end{array}$ & & & & \\
\hline $\begin{array}{l}\text { +leptotene } \\
\text { Zygotene }\end{array}$ & $\begin{array}{c}80 \pm 15 \\
267 \pm 152\end{array}$ & $\begin{array}{r}71 \pm 16 \\
193 \pm 42\end{array}$ & & \\
\hline $\begin{array}{l}\text { Pachytene + diplotene } \\
\quad+\text { diakinesis + secondary } \\
\text { spermatocytes } \\
\text { Spermatids }\end{array}$ & $1697 \pm 24$ & $1746 \pm 45$ & & \\
\hline $\begin{array}{l}\text { 1st layer } \\
\text { 2nd layer }\end{array}$ & $\begin{array}{l}2893 \pm 311 \\
2445 \pm 42\end{array}$ & $\begin{array}{l}2673 \pm 145 \\
2207 \pm 184\end{array}$ & & \\
\hline
\end{tabular}

Values are means \pm s.d. in 30 tubular cross-sections of 8 testes from 4-month-old mice. ${ }^{*} P<0.05$ compared with value for intact mice (Student's $t$ test).

Table 2. Labelling index of mice spermatogonia $4 \mathrm{~h}$ after $\left[{ }^{3} \mathrm{H}\right]$ thymidine injection

\begin{tabular}{|c|c|c|c|}
\hline \multirow{2}{*}{$\begin{array}{l}\text { Condition } \\
\text { of testes }\end{array}$} & \multirow{2}{*}{$\begin{array}{c}\text { Spermatogonia } \\
\text { type }\end{array}$} & \multicolumn{2}{|c|}{ Genotype* } \\
\hline & & $W /+$ & $+1+$ \\
\hline Intact & $\begin{array}{l}\text { Type A } \\
\text { Intermediate-B }\end{array}$ & $\begin{array}{l}50 \cdot 3 \pm 8 \cdot 1 \\
56 \cdot 1 \pm 4 \cdot 6\end{array}$ & $\begin{array}{l}55 \cdot 0 \pm 3 \cdot 7 \\
57 \cdot 1 \pm 11 \cdot 7\end{array}$ \\
\hline Cryptorchid & Type A & $47.7 \pm 7.7$ & $57.0 \pm 11.7$ \\
\hline
\end{tabular}

Values are means \pm s.d. $\%$ of labelled spermatogonia in 30 tubular cross-sections for 6 testes.

$* W /+$ for white belly spot.

of testicular germ-cell differentiation (Nishimune et al., 1978), demonstrating recovery and regenerative differentiation from spermatogonia (Nishimune et al., 1980).

\section{Materials and Methods}

Mice. Mice of the genotypes $W /+$ and $+/+$ were studied. Original stocks were derived from the Jackson Laboratory, Bar Harbor, Maine, USA. The presence of the $W$ gene was inferred from the presence of a white belly spot. Normal littermates were used as the control animals.

Experimental cryptorchidism and its surgical reversal. Experimental cryptorchidism was carried out on 2-monthold mice as previously described (Nishimune et al., 1978). After 2 months, 4 mice of each genotype were killed. In the remaining animals, the cryptorchidism was surgically reversed and 4 mice were killed on Days 17 or 60 after operation. Three age-matched intact animals of each genotype were used as controls for cryptorchidism or its surgical reversal. The testes, prostate glands and seminal vesicles with coagulating glands were removed and weighed. The testes were fixed in Bouin's solution, sectioned at a thickness of $5 \mu \mathrm{m}$, stained with Mayer's haematoxylin and eosin and then examined under a light microscope. The numbers of different types of germ cell were compared as number observed in 30 cross-sections of seminiferous tubules/testis, according to the criteria of Leblond \& Clermont (1952) and Oakberg (1956). The stages of spermatogenesis in surgically reversed testes were determined, based on the association of intermediate-Type B spermatogonia, spermatocytes and spermatids according to Oakberg (1956). 


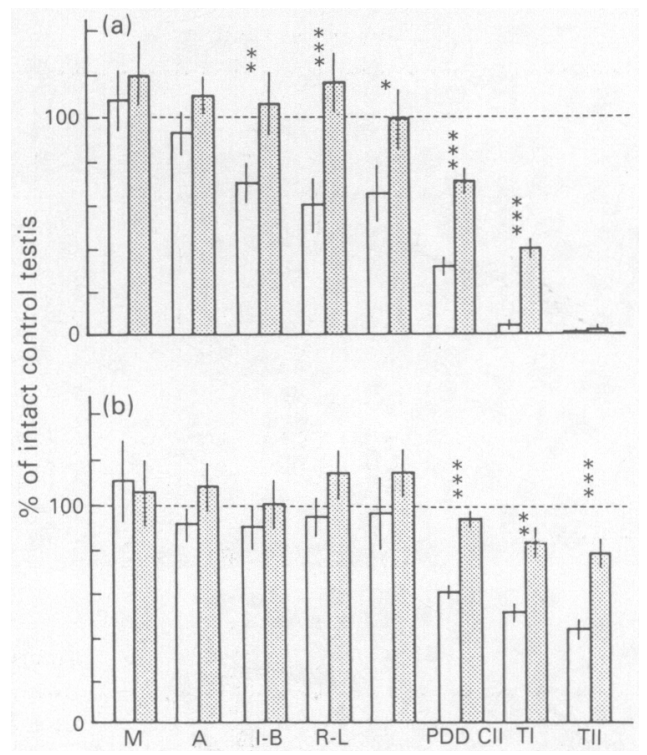

Fig. 1. Differentiation of germ cells after surgical reversal of experimental cryptorchidism. Values are means \pm s.d. of counts in 30 tubular cross-sections in testes from each of 4 mice (8 testes) sampled on Days 17 (a) and 60 (b) after surgical reversal of experimental cryptorchidism. Data are expressed as \% of the numbers of cells in the testes of 3 intact animals ( 6 testes) of the same age for each genotype; ( $\square) W /+$ (white belly spot), ( $($ ) $)+/+. \mathbf{M}=$ mitotic cells, $\mathrm{A}=$ Type A spermatogonia, I-B = intermediate-Type B spermatogonia, $\mathbf{R}-\mathbf{L}=$ resting primary-leptotene spermatocyte, $\mathrm{Z}=$ zygotene spermatocyte, $\mathrm{PDDCII}=$ pachytene-diplotene-diakinesis-secondary spermatocyte; $\mathrm{TI}=$ spermatids at first layer, $\mathrm{TII}=$ spermatids at second layer. Asterisks indicate the significant difference between $W /+$ and $+/+$ genotypes: ${ }^{*} P<0.05,{ }^{* *} P<0.02,{ }^{* * *} P<0.01$.

Autoradiography. Six 4-month-old mice of each genotype were injected intraperitoneally with $20 \mu \mathrm{Ci}\left[{ }^{3} \mathrm{H}\right]$ thymidine (specific activity $20 \mu \mathrm{Ci} / \mathrm{mmol}$ ) in $0.20 \mathrm{ml}$ Dulbecco's phosphate-buffered saline. To examine the DNA synthesis in spermatogonia, 3 mice of each genotype were killed $4 \mathrm{~h}$ after injection. The progress of germ-cell differentiation was examined by killing the other 3 mice 20 days after injection. The testes were fixed and sectioned as above. Samples were dipped in autoradiographic emulsion (Konisiroku, Tokyo, Japan), air dried and then exposed for 30 days at $4^{\circ} \mathrm{C}$. After developing, the samples were stained with Mayer's haematoxylin and eosin.

\section{Results}

\section{Germ cell differentiation in $W /+$ mice}

Histological analysis of testicular cross-sections showed no abnormality in $W /+$ testes. The numbers of different types of germ cell and Sertoli cells in 30 tubular cross-sections in $W /+$ testes were similar to those in $+/+$ testes (Table 1 ). In mouse testes, $\left[{ }^{3} \mathrm{H}\right]$ thymidine is exclusively incorporated into DNA of the spermatogonia and resting primary spermatocytes (Monesi, 1962). On Day 20 after $\left[{ }^{3} \mathrm{H}\right.$ ]thymidine injection, differentiation of labelled spermatogonia and spermatocytes has proceeded to spermatids (Nebel et al., 1961; Ghosal \& Mukherjee, 1971; Kluin et al., 1982). Most advanced germ cells having silver grains and most immature ones were at the second and first layers of spermatids, respectively, in the testes of $+/+$ and $W /+$ mice. Labelled spermatogonia and spermatocytes were absent. There were no differences in labelling index of spermatids at the first and second layer for the two genotypes $(10 \cdot 8 \pm 2.8$ and $47 \cdot 7 \pm 4 \cdot 1 \%$ in $W /+; 16.5 \pm 4 \cdot 0$ 
(a)

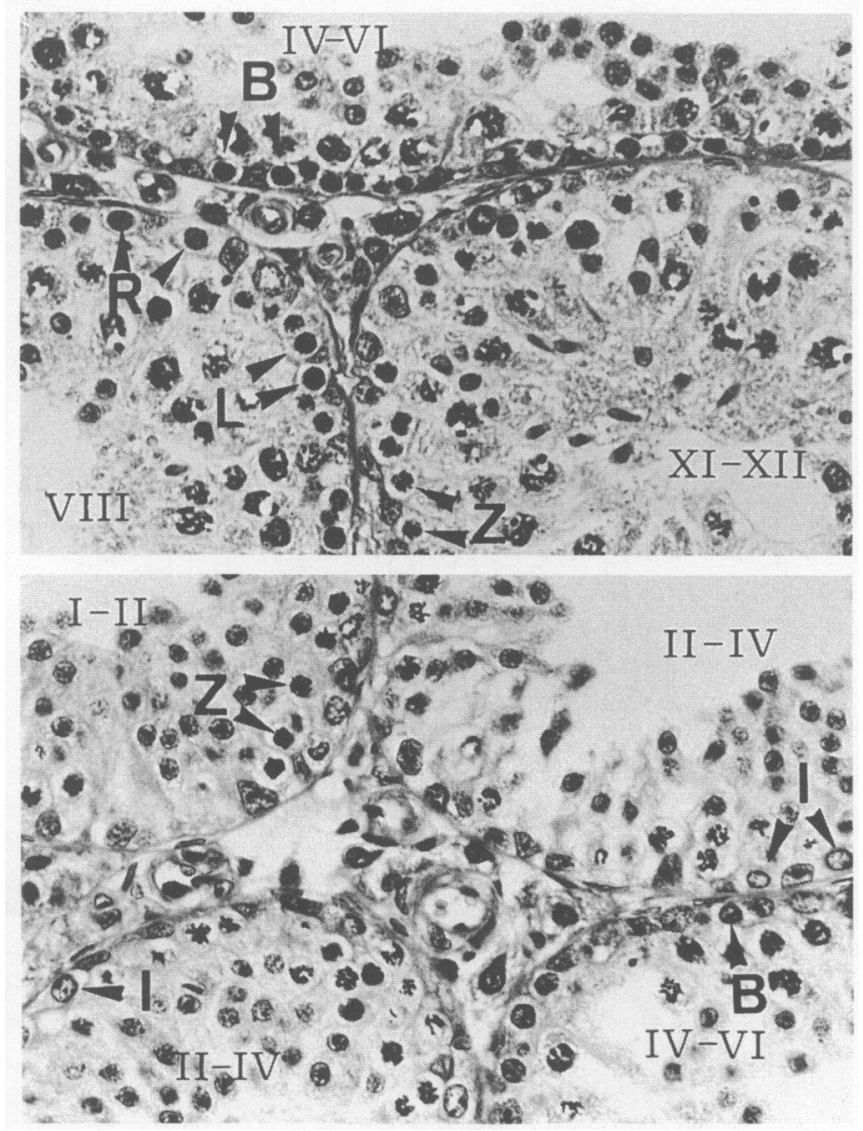

Fig. 2 (a).

and $47 \cdot 3 \pm 15 \cdot 1 \%$ in $+/ t$, respectively). These results indicate that germ cell differentiation in $W /+$ testes proceeds normally.

\section{Effect of experimental cryptorchidism on $\mathrm{W} /+$ testes}

Transplantation of the testes to the abdominal cavity in adult mice (artificial cryptorchidism) causes degeneration of the germinal epithelium. Most of the differentiated germ cells degenerated, leaving only undifferentiated Type A spermatogonia and some mitotic cells as the germ cell element (Nishimune et al., 1978). These mitotic cells were considered to be mitotic Type A spermatogonia, since Sertoli cells do not proliferate in adult testes (Steinberger \& Steinberger, 1971). In neither of the genotypes were intermediate-Type B spermatogonia, spermatocytes or spermatids observed. The numbers of mitotic cells and Type A spermatogonia in $W /+$ testes were similar to those in $+/+$ testes (Table 1). Although there were more Sertoli cells in cryptorchid testes than in intact testes in both genotypes, the slight increase might be due to shrinkage of the seminiferous tubules caused by the depletion of differentiated germ cells. The proportion of Type A spermatogonia to Sertoli cells in cryptorchid testes was similar to that in intact testes. The labelling index of Type A spermatogonia and the number of mitotic cells were not different in testes of $W /+$ and $+/+$ mice in any of the experimental conditions (Tables $1 \& 2$ ). Thus, no significant difference was observed between $\mathrm{W} /+$ and $+/+$ testes in either the number and cell cycle progression of Type A spermatogonia. 
(b)

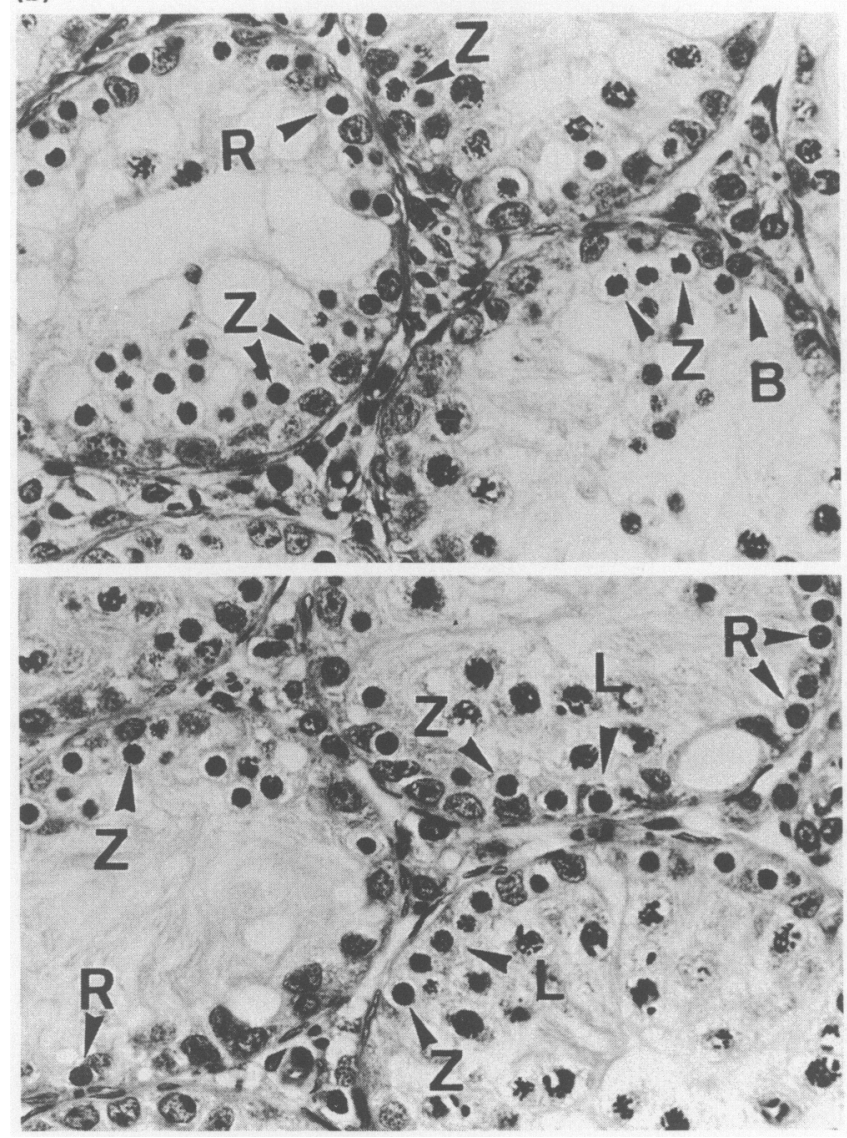

Fig. 2 (b).

Fig. 2. Cross-sections of the testes of (a) $+/+$ and (b) $W /+$ (white belly spot) mice on Day 17 after surgical reversal of cryptorchidism. Roman numerals in (a) indicate the stage of seminiferous epithelium cycle. Intermediate (I), Type B spermatogonia (B), resting primary (R), leptotene $(\mathrm{L})$ and zygotene $(\mathrm{Z})$ spermatocytes are indicated. Magnification $\times 800$.

Table 3. Weights of testes, prostate glands and seminal vesicles with coagulating glands in $W /+$ (white belly spot) and $+/+$ mice

\begin{tabular}{lrrrrr}
\hline & \multicolumn{2}{c}{ Intact } & & \multicolumn{2}{c}{ Cryptorchid } \\
\cline { 2 - 3 } \cline { 5 - 6 } Organ weight & \multicolumn{1}{c}{$W /+$} & \multicolumn{1}{c}{$+/+$} & & \multicolumn{1}{c}{$W /+$} & \multicolumn{1}{c}{$+/+$} \\
\hline Testes (mg) & $83.3 \pm 3.9$ & $88.3 \pm 4.3$ & & $19.0 \pm 1.1$ & $20.0 \pm 1.3$ \\
Prostate glands (mg) & $5.3 \pm 0.3$ & $5.7 \pm 0.3$ & & $5.8 \pm 1.3$ & $5.6 \pm 1.5$ \\
Seminal vesicles with & & & & & \\
$\quad$ coagulating glands (mg) & $215.3 \pm 1.1$ & $229.8 \pm 60.8$ & & $189.8 \pm 23.8$ & $240.5 \pm 43.1$ \\
Body weight (g) & $26.2 \pm 0.8$ & $27.4 \pm 0.4$ & & $26.5 \pm 1.8$ & $26.9 \pm 2.7$ \\
\hline
\end{tabular}

The values are means \pm s.d. for 8 animals. 


\section{Differentiation of germ cells after surgical reversal}

In wild-type mice $(+/ t)$, the first wave of regenerative differentiation proceeded to spermatids from Type A spermatogonia by 17 days after surgical reversal (Nishimune et al., 1978). On Day 60, germ-cell differentiation had proceeded further and mature spermatozoa had been produced. Regenerative differentiation was estimated by differential scoring of the number of each type of germ cell. There were fewer regenerating germ cells in $W /+$ testes than in $+/+$ testes (Fig. 1). On Day 17 , statistically significant differences between $W /+$ and $+/+$ mice were found for intermediate-Type B spermatogonia $(P<0.02)$, resting primary-leptotene spermatocyte $(P<0.01)$, zygotene spermatocyte $(P<0.05)$, pachytene-diakinesis-diplotene-secondary spermatocyte $(P<0.01)$ and spermatid I $(P<0.01)$ stages by Student's $t$ test. The proportions of intermediate-Type B spermatogonia, spermatocytes and spermatids in $W /+$ testes to that in $+/+$ testes were $\sim 70,50$ and $15 \%$, respectively (Fig. 1a). Even on Day 60 after surgical reversal, germcell regeneration in $W /+$ testes was retarded. Although the numbers of intermediate-Type $B$ spermatogonia, resting primary-leptotene spermatocyte and zygotene spermatocyte in $W /+$ testes were similar to those in $+/+$ testes, a significant difference was found in that of pachytenediplotene-diakinesis-secondary spermatocyte $(P<0.01)$, and spermatid I $(P<0.02)$ and II stages $(P<0.01)$ : the proportion of spermatocytes and spermatids in $W /+$ testes to that in $+/+$ testes was $\sim 60 \%$ (Fig. 1b). The patterns of germ cell associations in seminiferous epithelium of $+/ t$ mice on Day 17 after surgical reversal were normal. The presumptive stages of each tubule could be defined (Fig. 2a). On the other hand, $W /+$ mice on Day 17 after operation revealed atypical cell associations that could not be classified at this stage (Fig. 2b). In about half of the seminiferous tubules, Type B spermatogonia, resting primary spermatocyte, leptotene, zygotene spermatocytes were found in the same seminiferous tubule in the cross-section of $W /+$ testis. These cells did not coexist in the same tubule of $+/+$ mice. On Day 60 after surgical reversal, mutation effects on spermatogonia were not observed. Seminiferous epithelium of $W /+$ mice revealed normal cell associations in spite of reduction of pachytene spermatocytes and spermatids (data not shown). The $W /+$ mice did recover fertility, 4 months after surgical reversal, as compared with $2-3$ months in $+/+$ mice. These results indicated some retardation of germ-cell differentiation in the heterozygous $W$ mutant.

\section{Weight of sex organs}

There was no significant difference between the weights of $W /+$ and $+/+$ testes, prostate glands and seminal vesicles with coagulating glands (Table 3). These results suggested that androgen production in Leydig cells was not impaired in $W /+$ testes.

\section{Discussion}

The results show that the mutation at the $W$ locus affects not only primordial germ cells and oocytes but also adult spermatogenic cell differentiation (Coulombre \& Russell, 1954; Mintz \& Russell, 1956; Mintz, 1957). In intact adult $W /+$ mice, this effect of the mutant gene was not observed. The regenerative differentiation of intermediate-Type B spermatogonia, spermatocytes and spermatids was clearly retarded in the surgically reversed testes of $W /+$ mice, but neither an increase in degenerating germ cells nor an accumulation of any specific type of germ cell was observed (Fig. 1). Abnormal cell associations of $W /+$ mice (Fig. 2b) indicated that germ-cell differentiation proceeded asynchronously. This may be a due to an increase in the duration of the cell cycle of a portion of germ cells. Although the function of Type A spermatogonia seemed to be normal, judging from the number of mitotic cells and the labelling index (Tables $1 \& 2$ ), the cell cycle of Type A spermatogonia might be prolonged without an increase in their number. If the $W$ mutation affects spermatogonial differentiation, forming intermediate-Type B spermatogonia but 
not further steps of spermatogenesis, the reduction of spermatocyte and spermatids might be a secondary effect caused by abnormal cell association in seminiferous epithelium that resulted in malfunction of Sertoli cells. Alternatively, the $W$ mutation might affect entire steps of spermatogenesis, then meiosis and haploid cell maturation were also interrupted by direct action of the mutant gene.

The type of cells in the testis that is impaired primarily by this mutation is still unclear. Although hormonal function plays an important role in spermatogenesis, androgen production in $W /+$ testes appeared to be normal, judging from the weight of accessory sex organs (Table 3 ). These results suggest that the retardation of germ-cell differentiation in $W /+$ testes is due to a defect in cells of the seminiferous tubules.

Reports have indicated that the $W$ gene encodes the proto-oncogene c-kit (Chabot et al., 1988; Geissler et al., 1988). The gene product of $c$-kit is a transmembrane receptor with tyrosine kinase activity is affected by $W$ mutations. Moreover, the ligand of c-kit was identified recently (Flanagan \& Leder 1990; Huang et al., 1990; Zsebo et al., 1990). This ligand (KL (kit ligand), SCF (stem cell factor) ) is a novel cell-surface protein that is a gene product of Steel locus. It is of interest whether the c-kit-KL/SCF signal transduction system is linked with other factors involved in the regulation of spermatogenesis. The action of a mitogenic factor such as interleukin 1 (Pollanen et al., 1989) or inhibitory factor such as inhibin (van Dissel-Emiliani et al., 1989) on spermatogonia may be mediated by the c-kit-KL/SCF system. Identifying the cells which produce factors and which express the receptors is important to resolve the modes at interactions between these factors.

We thank E. M. Thompson for help in preparing the manuscript.

\section{References}

Chabot, B., Stephenson, D.A., Chapman, V.M., Besmer, P. \& Bernstein, A. (1988) The proto-oncogene c-kit encoding a transmembrane tyrosine kinase receptor maps to the mouse $W$ locus. Nature, Lond. 335, 88-89.

Coulombre, J.L. \& Russell, E.S. (1954) Analysis of the pleiotropism at the $\mathrm{W}$-locus in the mouse: the effect of $W$ and $W^{\mathrm{v}}$ substitution upon postnatal development of germ cells. J. exp. Zool. 126, 277-296.

Flanagan, J.G. \& Leder, P. (1990) The kit ligand: a cell surface molecule altered in steel mutant fibroblasts. Cell 63, 185-194.

Geissler, E., McFarland, E.C. \& Russell, E.S. (1981) Analysis of pleiotropism at the dominant white spotting $(W)$ locus of the house mouse: a description of ten new $W$ alleles. Genetics, Princeton 97, 337-361.

Geissler, E.N., Ryan, M.A. \& Housman, D.E. (1988) The dominant spotting $(W)$ locus of the mouse encodes the c-kit proto-oncogene. Cell 55, 185-194.

Ghosal, S.K. \& Mukherjee, B.B. (1971) The chronology of DNA synthesis, meiosis and spermiogenesis in the male mouse and golden hamster. Can. J. Genet. Cytol. 13, 672-682.

Grüneberg, H. (1942) Inherited macrocytic anemias in the house mouse: II. Dominance relationships. $J$. Genet. 43, 285-293.

Huang, E., Nocka, K., Beier, D.R., Chu, T., Buck, J., Lahm, H., Wellner, D., Leder, P. \& Besmer, P. (1990) The hematopoietic growth factor KL is encoded by the $S l$ locus and is the ligand of the c-kit receptor, the gene product of the $W$ locus. Cell 63, 225-233.

Kitamura, Y., Go, S. \& Hatanaka, K. (1978) Decrease of mast cells in $W / W^{v}$ mice and their increase by bone marrow transplantation. Blood 52, 447-452.
Kluin, P.M., Kramer, M.F. \& de Rooij, D.G. (1982) Spermatogenesis in the immature mouse proceeds faster than in the adult. Int. J. Androl. 5, 282-294.

Leblond, C.P. \& Clermont, Y. (1952) Definition of the stages of the cycle of the seminiferous epithelium in the rat. Ann. N.Y. Acad. Sci. 55, 548-573.

Mayer, T.C. \& Green, M.C. (1968) An experimental analysis of pigment defect caused by mutations at $W$ and $S /$ loci in mice. Devl Biol. 18, 62-75.

Mayer, T.C. (1970) A comparison of pigment cell development in albino, steel, and dominant-spotting mouse embryo. Devl Biol. 23, 297-309.

McCulloch, E.A., Siminovitch, L. \& Till, J.E. (1964) Spleen colony formation in anemic mice of genotype $W / W^{\vee}$. Science, $N Y 144,844-846$

Mintz, B. (1957) Embryological development of primordial germ cells in the mouse: influence of a new mutation, $W^{j}$. J. Embryol. exp. Morphol. 5, 396-403.

Mintz, B. \& Russell, E.S. (1957) Gene-induced embryological modifications of primordial germ cells in the mouse. J. exp. Zool. 134, 207-237.

Monesi, V. (1962) Autoradiographic study of DNA synthesis and the cell cycle in spermatogonia and spermatocytes of mouse testis using tritiated thymidine. J. Cell Biol. 14, 1-18.

Nebel, B.R., Amarose, A.P. \& Hackett, E.M. (1961) Calendar of gametogenic development in the prepubertal male mouse. Science, $N Y 134,832-833$.

Nishimune, Y., Aizawa, S. \& Komatsu, T. (1978) Testicular germ cell differentiation in vivo. Fert. Steril. 29, 95-102. 
Nishimune, Y., Haneji, T. \& Kitamura, Y. (1980) The effect of steel mutation on testicular germ cell differentiation. J. cell. Physiol. 105, 137-141.

Oakberg, E.F. (1956) A description of spermiogenesis in the mouse and its use in analysis of the cycle of the seminiferous epithelium and germ cell renewal. Am. J. Anat. 99, 391-413.

Pollanen, P., Soder, O. \& Parvinen, M. (1989) Interleukin$1 \alpha$ stimulation of spermatogonial proliferation in vivo. Reprod. Fert. Dev. 1, 85-87.

Russell, E.S. \& Fondal, E.L. (1951) Quantitative analysis of the normal and four alternative degrees of an inherited macrocytic anemia in the house mouse: $I$. Number and size of erythrocytes. Blood 6, 892-905.

Russell, E.S. \& Bernstein, S.E. (1968) Proof of wholecell implant in therapy of W-series anemia. Arch. Biochem. Biophys. 125, 594-597.

Russell, E.S. (1979) Hereditary anemias of the mouse: a review for geneticists. Adv. Genet. 20, 357-459.
Steinberger, A. \& Steinberger, E. (1971) Replication pattern of Sertoli cells in maturing rat testis in vivo and in organ culture. Biol. Reprod. 4, 84-87.

van Dissel-Emiliani, F.M., Grootenhuis, A.J., de Jong, F.H. \& de Rooij, D.G. (1989) Inhibin reduces spermatogonial numbers in testes of adult mice and Chinese hamsters. Endocrinology 125, 1898-1903.

Zsebo, K.M., Williams, D.A., Geissler, E.N., Broudy, V.C., Martin, F.H., Atkins, H.L., Hsu, R., Birkett, N.C., Okino, K.H., Murdock, D.C., Jacobsen, F.W., Langley, K.E., Smith, K.A., Takeishi, T., Cattanach, B.M., Galli, S.J. \& Suggs, S.V. (1990) Stem cell factor is encoded at the $\mathrm{Sl}$ locus of the mouse and is the ligand for the c-kit tyrosin kinase receptor. Cell 53, 213-224. 